\title{
MicroRNA-146a regulates the transformation from liver fibrosis to cirrhosis in patients with hepatitis B via interleukin-6
}

\author{
ZHAOHUI YANG, YULONG PENG and SUXIAN YANG \\ Department of Infection, Linyi People's Hospital, Linyi, Shandong 276003, P.R. China
}

Received October 31, 2016; Accepted October 8, 2017

DOI: $10.3892 /$ etm.2019.7490

\begin{abstract}
The aim of the present study was to measure the expression of microRNA (miR)-146a in liver tissues, peripheral blood mononuclear cells (PMBC) and serum from patients with Hepatitis B and either liver fibrosis or cirrhosis, as well as to determine the regulatory mechanism of miR-146a. A total of 36 patients with Hepatitis B and liver fibrosis and 25 patients with hepatitis B and liver cirrhosis admitted to Linyi People's Hospital (Shandong, China) between June 2012 and February 2016 were included in the present study. Reverse transcription-quantitative polymerase chain reaction was performed to determine the expression of miR-146a and interleukin (IL)-6 mRNA in the liver tissue, PBMCs and serum. Western blotting was used to assess the expression of IL-6 in liver tissues and PBMCs. An enzyme-linked immunosorbent assay was conducted to measure IL-6 levels in serum. To identify the direct interaction between IL-6 and miR-146a, a dual luciferase reporter assay was performed. IL-6 mRNA expression in liver tissues, PBMCs and serum from patients with liver cirrhosis was significantly higher than that from patients with liver fibrosis $(\mathrm{P}<0.05)$. Furthermore, IL-6 expression in liver tissues and PBMCs from patients with liver cirrhosis was enhanced and levels of IL-6 protein in the serum of patients with liver cirrhosis were significantly elevated compared with patients with liver fibrosis $(\mathrm{P}<0.05)$. By contrast, levels of miR-146a in liver tissues, PBMCs and serum from patients with liver cirrhosis were significantly downregulated $(\mathrm{P}<0.05)$ compared with patients with liver fibrosis. miR-146a regulated the expression of IL- 6 by binding to its 3'-untranslated region. Thus, in the transformation from liver fibrosis to cirrhosis, the upregulation of IL-6 in liver tissues, PBMCs and serum may be associated with the downregulation of miR-146a. miR-146a directly targets IL-6, which may regulate the occurrence and immune responses of Hepatitis B.
\end{abstract}

Correspondence to: Dr Suxian Yang, Department of Infection, Linyi People's Hospital, 27 East Jiefang Road, Linyi, Shandong 276003, P.R. China

E-mail: cdx3578@126.com

Key words: microRNA-146a, hepatitis B, fibrosis, interleukin-6, cirrhosis

\section{Introduction}

Liver fibrosis is usually observed in chronic liver diseases with different causes and its morphology is characterized by the deposition of a large amount of extracellular matrix in liver tissues (1). Liver fibrosis may progress into cirrhosis that threatens the health and life of patients (2). Chronic Hepatitis B can cause liver inflammation and fibrosis. If not detected promptly and treated, patients can develop cirrhosis (3). Decompensated cirrhosis has poor prognosis and can easily develop into hepatocellular carcinoma, a serious and life-threatening complication of cirrhosis $(4,5)$. A previous prospective study determined that the annual rate of conversion from chronic Hepatitis B into liver cirrhosis is $2.1 \%$ (6). A follow-up study of HBeAg-negative patients with chronic Hepatitis B over an average of 9 years (1-18.4 years) demonstrated that the percentage of patients who developed liver cirrhosis was $23 \%(7,8)$. Interferon and nucleotide analogues are currently used in the treatment of Hepatitis B virus (9). In addition to antiviral therapy, the treatment of hepatic fibrosis and cirrhosis following Hepatitis B infection needs to strengthen hepatocyte regeneration, inhibit inflammation and reduce the risk of further complications $(10,11)$. Therefore, it is important to investigate the mechanism of the transformation from liver fibrosis to cirrhosis at the molecular level in order to develop novel treatments for Hepatitis B.

MicroRNA (miR) molecules are a type of non-encoding small RNA molecule that are 18-22 nucleotides long and can regulate the expression of proteins at the mRNA level (12-14). The processes of liver fibrosis and cirrhosis are accompanied by alterations in the expression of different miRs and proteins, suggesting that miR may serve important roles in regulating the expression of proteins associated with liver fibrosis and cirrhosis $(15,16)$. Hepatitis B may also induce inflammation to a certain extent $(17,18)$, which, in turn, may lead to the development of liver cancer $(19,20)$. Previous studies have demonstrated that the inflammatory factor interleukin (IL)- 6 serves a key role in the onset of hepatitis B $(21,22)$. However, the regulation of liver fibrosis and cirrhosis by IL- 6 and the mechanism by which miRs regulate IL- 6 remain unclear. In the present study, the expression of IL- 6 mRNA and protein in patients with liver fibrosis and cirrhosis was assessed and the association between miR-146a and IL-6 was evaluated. 


\section{Materials and methods}

Patient samples. A total of 36 patients with Hepatitis B and liver fibrosis and 25 patients with Hepatitis B and liver cirrhosis admitted to the Linyi People's Hospital (Linyi, China) between June 2012 and February 2016 were included in the present study. Among the 36 patients with liver fibrosis, 20 were male and 16 were female, and they had a median age of 41 years (age range, 20-61 years). Among the 25 patients with liver cirrhosis, 15 were male and 10 were female, and they had a median age of 43 years (age range, 18-65 years). All patients were diagnosed with liver fibrosis or cirrhosis according to the guidelines for the prevention and treatment of chronic Hepatitis B (23). The levels of alanine aminotransferase and aspartate aminotransferase were determined in patients with liver fibrosis using an automatic biochemical analyzer (Beckman Coulter, Inc., Brea, CA, USA). The normal concentrations in the blood for alanine aminotransferase and aspartate aminotransferase levels were 0-40 and 5-40 U/1, respectively. The levels of alanine aminotransferase and aspartate aminotransferase in patients with liver fibrosis were $168.6 \pm 39.6$ and $146.2 \pm 28.5 \mathrm{U} / 1$, respectively. The levels of alanine aminotransferase and aspartate aminotransferase in patients with liver cirrhosis were $182.8 \pm 51.9$ and $161.2 \pm 39.3 \mathrm{U} / 1$, respectively. Patients with immune-related diseases or immune diseases, including diabetes and cancer, were excluded from the current study. Liver biopsies (1.0-1.5 cm in length) and peripheral blood samples $(20 \mathrm{ml})$ were collected from each patient. Blood serum was isolated from peripheral blood following centrifugation at $400 \mathrm{x}$ g for $10 \mathrm{~min}$ at $4^{\circ} \mathrm{C}$. To obtain peripheral blood mononuclear cells (PMBCs), a mixture of heparin-anticoagulant venous blood and equal amount of serum-free Iscove's modified Dulbecco's medium (1:1 v/v) was added gently to the lymphocyte separation medium before centrifugation at $400 \mathrm{xg}$ for $30 \mathrm{~min}$ at $4^{\circ} \mathrm{C}$. After centrifugation, the middle layer was aspirated and mixed with 5 volumes of Hanks solution before centrifugation at $300 \mathrm{x} \mathrm{g}$ for $10 \mathrm{~min}$ at $4^{\circ} \mathrm{C}$, washed twice and cell density was adjusted to $1 \times 10^{6}$ cells $/ \mathrm{ml}$. Cells were seeded into six-well plates at a density of $3 \times 10^{6}$ cells/well and incubated at $37^{\circ} \mathrm{C}$ in a $5 \% \mathrm{CO}_{2}$-humidified incubator for $1-2 \mathrm{~h}$. The cells that attached after 1-2 $\mathrm{h}$ incubation were PBMCs. All procedures were approved by the Ethics Committee of Linyi People's Hospital and written informed consent was obtained from all patients or their families.

Reverse transcription-quantitative polymerase chain reaction $(R T-q P C R)$. Prior to total RNA extraction, tissue samples (100 mg) were ground into powder using liquid nitrogen. Total RNA was extracted using $1 \mathrm{ml}$ TRIzol ${ }^{\circledR}$ (10606ES60; Shanghai Yeasen Biotechnology, Co., Ltd., Shanghai, China). Following lysis, miRNA was isolated using the miRcute miRNA isolation kit (Tiangen Biotech Co., Ltd., Beijing, China). The purity of RNA was determined at A260/A280 using an ultraviolet spectrophotometer (NanoDrop ND1000; Thermo Fisher Scientific, Inc., Wilmington, DE, USA). The TIANScript II cDNA First Chain Synthesis kit (KR107; Tiangen, Biotech, Co., Ltd., Beijing, China) was used to reverse transcribe $1 \mu \mathrm{g}$ RNA into cDNA, which was stored at $-20^{\circ} \mathrm{C}$. The primer sequences used were as follows: IL- 6 forward, 5'-GGCACTGGCAGAAAACAACC-3' and reverse, 5'-GCA AGTCTCCTCATTGAATCC-3'; GAPDH, forward, 5'-GGG
AAACTGCGGCGTGAT-3' and reverse, 5'-AAAGGTGGA GGAGTGGGT-3'. The PCR reaction mixture $(20 \mu \mathrm{l})$ contained $10 \mu$ l SuperReal PreMix SYBR-Green (Tiangen Biotech Co., Ltd.), $0.5 \mu$ upstream primer, $0.5 \mu$ l downstream primer, $2 \mu \mathrm{l}$ cDNA and $7 \mu \mathrm{lddH_{2 }}$ O. The following thermocyclic conditions were used for the qPCR: Initial denaturation at $95^{\circ} \mathrm{C}$ for $30 \mathrm{sec} ; 45$ cycles of $95^{\circ} \mathrm{C}$ for $5 \mathrm{sec}$ and $57^{\circ} \mathrm{C}$ for $30 \mathrm{sec}$. The qPCR was performed on an iQ5 Real-Time PCR Detection system (Bio-Rad Laboratories, Inc., Hercules, CA, USA). The $2^{-\Delta \Delta \mathrm{Cq}}$ method was used to calculate the relative expression of IL-6 mRNA against the reference gene GAPDH (24). For miR-146a, the primer sequences were as follows: miR-146a forward, 5'-CGGCGGTGAGAACTGAATTCCA-3' and reverse, 5'-GTGCAGGGTCCGAGGT-3'; U6 forward, 5'-CTC GCTTCGGCAGCACA-3' and reverse, 5'-AACGCTTCACGA ATTTGCGT-3'. The following thermocyclic conditions were used for the qPCR: Initial denaturation at $95^{\circ} \mathrm{C}$ for $5 \mathrm{~min}$; 40 cycles of denaturation at $95^{\circ} \mathrm{C}$ for $10 \mathrm{sec}, 60^{\circ} \mathrm{C}$ for $20 \mathrm{sec}$ and $70^{\circ} \mathrm{C}$ for $10 \mathrm{sec}$. The qPCR was performed as above and the $2^{-\Delta \Delta \mathrm{Cq}}$ method was used to calculate the relative expression of miR-146a against the reference gene U6.

Western blotting. Total protein was extracted from tissues and PBMCs using radioimmunoprecipitation assay lysis buffer (600 $\mu \mathrm{l} ; 50 \mathrm{mM}$ Tris-base, $1 \mathrm{mM}$ EDTA, $150 \mathrm{mM} \mathrm{NaCl}$, $0.1 \%$ sodium dodecyl sulfate, $1 \%$ Triton $\mathrm{X}-100,1 \%$ sodium deoxycholate; Beyotime Institute of Biotechnology, Shanghai, China) according to the manufacturer's protocol. Following lysis for $50 \mathrm{~min}$ on ice, the mixture was centrifuged at $13,400 \times \mathrm{g}$ and $4^{\circ} \mathrm{C}$ for $5 \mathrm{~min}$. The supernatant was used to determine protein concentration using a bicinchoninic acid protein concentration determination kit [RTP7102; Real-Times (Beijing) Biotechnology Co., Ltd., Beijing, China]. Protein samples $(20 \mu \mathrm{g})$ were then mixed with sodium dodecyl sulfate loading buffer prior to denaturation in a boiling water bath for $5 \mathrm{~min}$. Afterwards, $50 \mu \mathrm{g}$ protein/lane was separated via SDS-PAGE on a $10 \%$ gel. Resolved proteins were then transferred to polyvinylidene difluoride membranes on ice $(100 \mathrm{~V}, 2 \mathrm{~h})$ and blocked with 5\% skimmed milk at room temperature for $1 \mathrm{~h}$. Subsequently, membranes were incubated with rabbit anti-human IL-6 polyclonal primary antibody $(1: 1,000 ;$ ab6672) and rabbit anti-human $\beta$-actin primary antibody (1:5,000; ab129348; both Abcam, Cambridge, UK) at $4^{\circ} \mathrm{C}$ overnight. Following three extensive washes with phosphate-buffered saline with Tween 20 for 15 min each time, membranes were incubated with goat anti-rabbit horseradish peroxidase-conjugated secondary antibody (1:3,000; ab6721; Abcam) for $1 \mathrm{~h}$ at room temperature prior to three washes with phosphate-buffered saline with Tween-20 for 15 min each time. Subsequently, the membrane was developed using an enhanced chemiluminescence detection kit (ab65623; Abcam) for imaging. Image lab v3.0 software (Bio-Rad Laboratories, Inc.) was used to acquire and analyze imaging signals. The relative content of IL- 6 protein was expressed as the IL-6/ $\beta$-actin ratio.

Enzyme-linked immunosorbent assay (ELISA). Serum samples were tested using an IL-6 ELISA kit (ab178013; Abcam). In microplates, standards $(50 \mu 1)$, samples $(10 \mu 1$ sample liquid and $40 \mu \mathrm{l}$ diluent) and blank were added to predefined wells. In the wells for standards and samples, horseradish 


\section{3' uuggguaccuuaaguCAAGAGu 5' hsa-miR-146a}

\section{||||||}

\section{8:5' cacagaacuuauguuGUUCUCu 3' IL-6}

Figure 1. Bioinformatics prediction of direct interactions between miR-146a and IL-6. miR, microRNA, IL, interleukin.

peroxidase-labeled conjugates $(100 \mu \mathrm{l})$ were added prior to sealing the plates for incubation at $37^{\circ} \mathrm{C}$ for $1 \mathrm{~h}$. Following five washes of the plates, substrates $\mathrm{A}(50 \mu \mathrm{l})$ and $\mathrm{B}(50 \mu \mathrm{l})$ were added to each well. Following incubation at $37^{\circ} \mathrm{C}$ for $15 \mathrm{~min}$, stop solution $(50 \mu \mathrm{l})$ was added to each well, and the absorbance of each well was measured at $450 \mathrm{~nm}$ within $15 \mathrm{~min}$.

Dual luciferase reporter assay. Bioinformatic predictions are a useful tool to use to evaluate miR function. To determine the regulation of IL-6 in liver fibrosis and cirrhosis, miRanda (www.microrna.org/rnicrorna/home.do), TargetScan (www.targetscan.org), PiTa (genie.weizmann. ac.il/pubs/mir07/mir07_data.html), RNAhybrid (bibiserv. techfak.uni-bielefeld.de/rnahybrid) and PICTA (pictar. mdc-berlin.de) were used to predict the miR molecules that regulate IL- 6 and indicated that miR-146a may regulate IL-6 (Fig. 1). According to the bioinformatic results, wild-type (WT) and mutant seed regions of miR-146a in the 3'-untranslated region (UTR) of IL-6 were chemically synthesized in vitro, SpeI and HindIII restriction sites were added, and the WT and mutant miR-146a were cloned into pMIR-REPORT luciferase reporter plasmids (Ambion; Thermo Fisher Scientific, Inc., Waltham, MA, USA). Plasmids
$(0.8 \mu \mathrm{g})$ with WT or mutant 3'-UTR DNA sequences were co-transfected with $100 \mathrm{nM}$ agomiR-146a (Sangon Biotech, Shanghai, China) into 293T cells were obtained from the Cell Bank of the Chinese Academy of Sciences (Shanghai, China). Following $24 \mathrm{~h}$ cultivation, cells were lysed using a dual luciferase reporter assay kit (Promega Corporation, Madison, WI, USA) according to the manufacturer's protocol and fluorescence intensity was measured using a GloMax 20/20 luminometer (Promega Corporation). Renilla fluorescence activity was used as internal reference to measure the fluorescence values of each group of cells.

Statistical analysis. The results were analyzed using SPSS 18.0 statistical software (SPSS, Inc., Chicago, IL, USA). The data are presented as the mean \pm standard deviation and were tested for normality. Multigroup measurement data were analyzed using one-way analysis of variance. In the case of homogeneity of variance, Least Significant Difference and Student-Newman-Keuls methods were used; in the case of heterogeneity of variance, Tamhane's T2 or Dunnett's T3 method were used. $\mathrm{P}<0.05$ indicated a statistically significant difference.

\section{Results}

IL-6 mRNA expression in liver tissues, PBMCs and serum from patients with liver cirrhosis is higher than that from patients with liver fibrosis. To measure the expression of IL-6 mRNA in the different samples, RT-qPCR was performed. The data indicated that levels of IL- 6 mRNA in liver tissues, PBMCs and serum from patients with liver cirrhosis were significantly increased compared with those from patients with liver fibrosis $(\mathrm{P}<0.05$; Fig. 2). These results suggest that
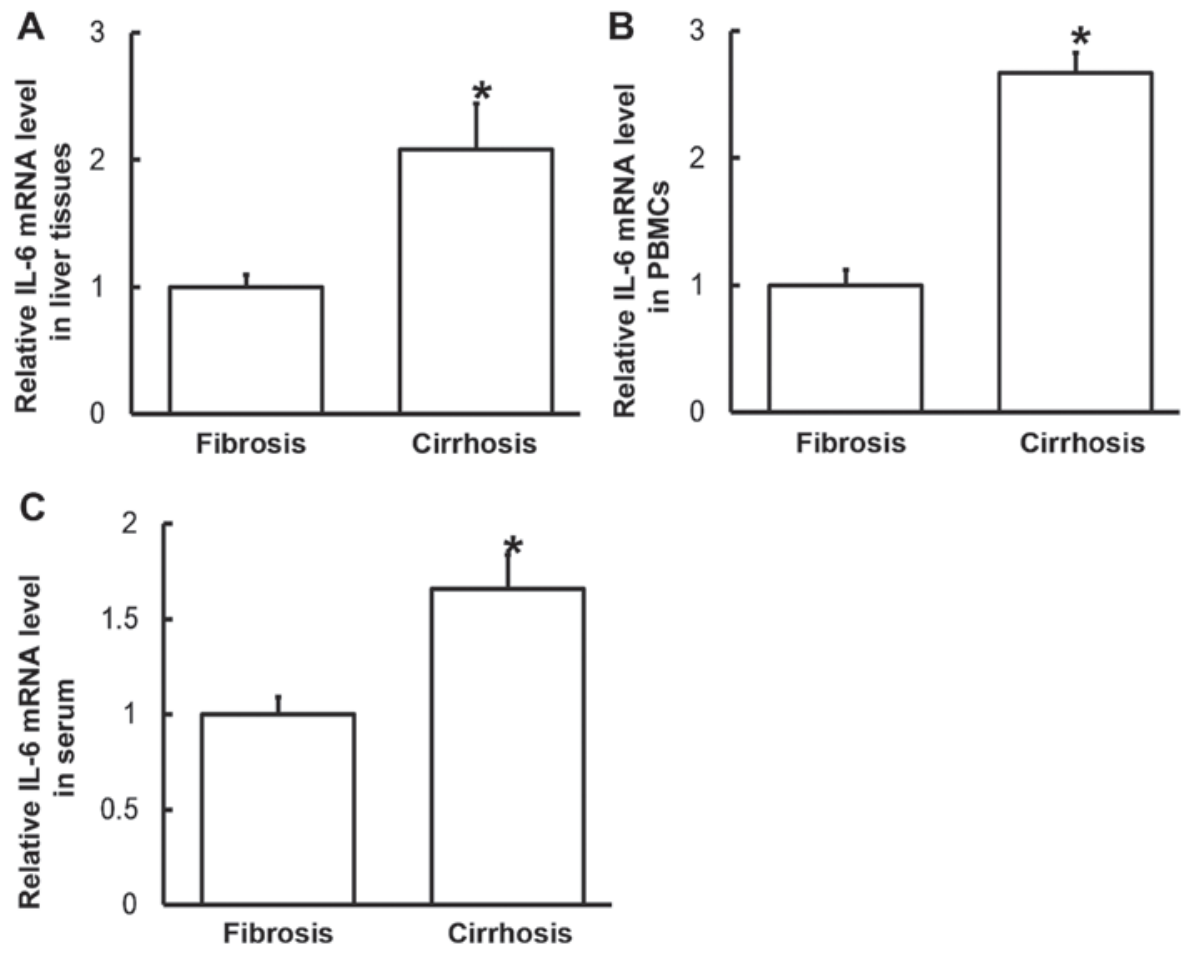

Figure 2. Expression of IL-6 mRNA in (A) liver tissues, (B) PBMCs and (C) serum of patients with hepatitis B and liver fibrosis or cirrhosis. Reverse transcription-quantitative polymerase chain reaction was used to determine $\mathrm{mRNA}$ expression. Data are presented as the mean + standard deviation. ${ }^{*}<0.05$ vs. patients with liver fibrosis. PBMC, peripheral blood mononuclear cells; IL, interleukin. 
A

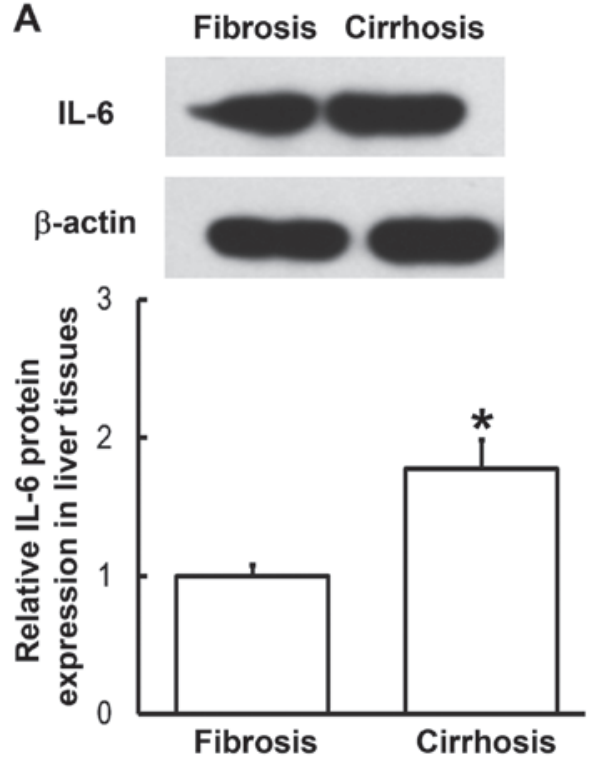

B

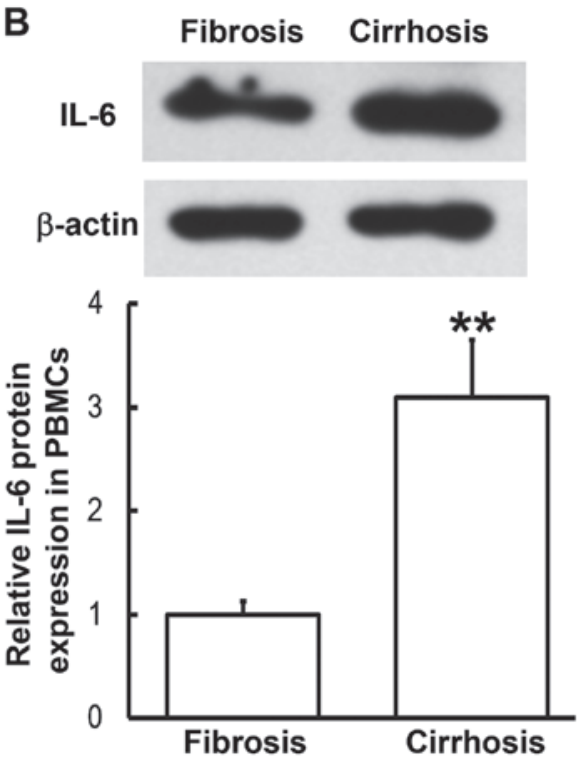

Figure 3. Expression of IL-6 protein in (A) liver tissues and (B) PBMCs from patients with hepatitis B and liver fibrosis or cirrhosis. Western blotting was used to measure protein expression. Data are presented as the mean + standard deviation. ${ }^{*} \mathrm{P}<0.05$; ${ }^{* *} \mathrm{P}<0.01$ vs. patients with liver fibrosis. IL-6, interleukin-6; PBMC, peripheral blood mononuclear cells.

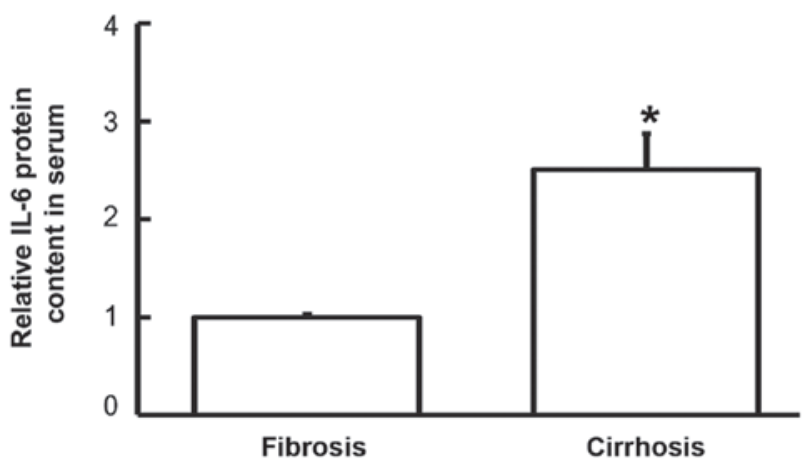

Figure 4. Levels of IL-6 protein in the serum of patients with hepatitis B and liver fibrosis or cirrhosis. ELISA was used to determine IL-6 levels Data are presented as the mean + standard deviation. Data are presented as the mean + standard deviation. ${ }^{*} \mathrm{P}<0.05$ vs. patients with liver fibrosis. IL-6, interleukin-6.

the expression of IL-6 mRNA in patients with liver cirrhosis is higher than in patients with liver fibrosis.

Expression of IL-6 protein in liver tissues and PBMCs from patients with liver cirrhosis is enhanced. To determine the expression of IL-6 protein in liver tissues and PBMCs, western blotting was performed. Compared with patients with liver fibrosis, the expression of IL-6 in liver tissues and PBMCs from patients with liver cirrhosis was significantly enhanced $(\mathrm{P}<0.05, \mathrm{P}<0.01$, respectively; Fig. 3). This was consistent the results from RT-qPCR. These results indicate that IL-6 exerts its regulatory effect on liver cirrhosis at the protein level.

IL-6 protein content in serum from patients with liver cirrhosis is elevated compared with patients with liver fibrosis. To examine the content of IL- 6 protein in the serum, ELISA was employed. The data demonstrated that IL- 6 levels in the serum of patients with liver cirrhosis were significantly higher that in patients with liver fibrosis $(\mathrm{P}<0.05$; Fig. 4). This suggests that increased IL-6 protein levels in serum may be released from PBMCs.

Altered IL-6 expression may be induced by miR-146a levels. To measure miR-146a levels in various samples, RT-qPCR was performed. Compared with patients with liver fibrosis, miR-146a levels in the liver tissues, PBMCs and serum from patients with liver cirrhosis were significantly downregulated $(\mathrm{P}<0.05, \mathrm{P}<0.05$ and $\mathrm{P}<0.01$, respectively; Fig. 5). These results indicate that altered IL- 6 expression may be induced by alterations in miR-146a levels.

miR-146a regulates the expression of $I L-6$ by binding to its 3'-UTR. To identify the interaction between miR-146a and IL-6, a dual luciferase reporter assay was performed. The data demonstrated that the fluorescence value of the WT group was significantly lower than that of the $\mathrm{NC}(\mathrm{P}<0.01)$, whereas that of the mutant group did not differ significantly from the control ( $P>0.05$; Fig. 6). The results suggest that miR-146a regulates the expression of IL- 6 by binding to its 3'-UTR.

\section{Discussion}

IL-6 is an interleukin that serves a variety of functions and is released during immune responses. Bacteria, endotoxin and dust particles may stimulate the production of IL-6 in the body (25). IL-6 serves important roles in immune responses, inflammation, cell differentiation, coagulation and the occurrence and development of tumors (26). The expression of IL-6 is markedly elevated in inflammatory responses caused by injury, trauma, stress and infection (27). In inflammation, IL-6 induces the production of $\mathrm{C}$-reactive protein and fibrinogen in the body, and promotes thrombogenesis (28). Additionally, elevated IL-6 levels induce the onset of inflammatory diseases including rheumatoid arthritis and Crohn's disease by binding to IL-6 receptors (29). In rheumatoid arthritis, IL-6 

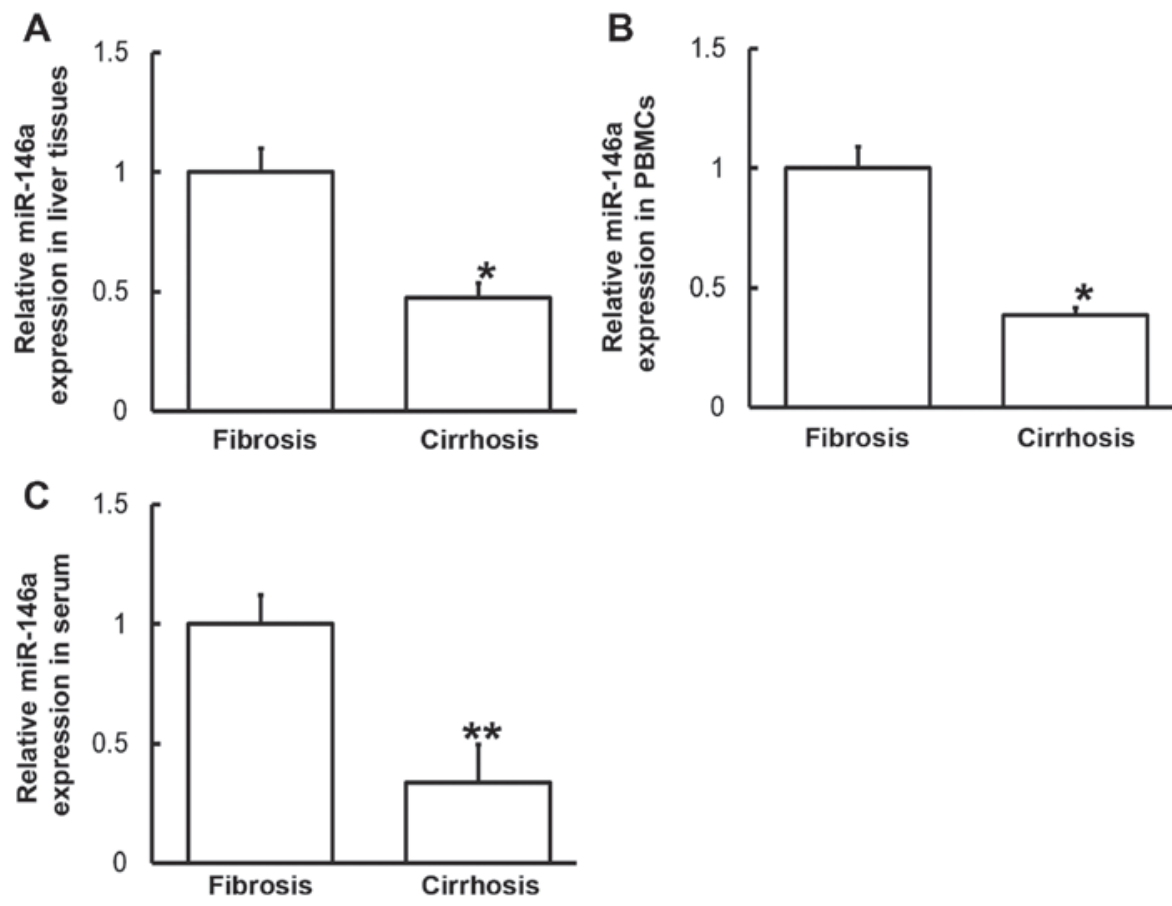

Figure 5. Expression of miR-146a in (A) liver tissues, (B) PBMCs and (C) serum of patients with hepatitis B and liver fibrosis or cirrhosis. Reverse transcription-quantitative polymerase chain reaction was used to determine miR-146a expression. Data are presented as the mean + standard deviation. ${ }^{*} \mathrm{P}<0.05 ;{ }^{* *} \mathrm{P}<0.01$ vs. patients with liver fibrosis. $\mathrm{PBMC}$, peripheral blood mononuclear cells; miR, microRNA.

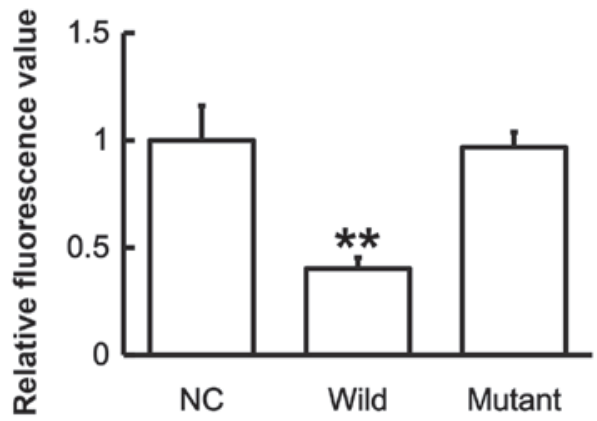

Figure 6. Fluorescence values of HEK293T cells transfected with wild-type or mutant 3'-UTR DNA sequences of IL-6 and agomiR-146a. A dual luciferase reporter assay was used to evaluate the interaction between miR-146a and IL-6. Data are presented as the mean + standard deviation. ${ }^{* *} \mathrm{P}<0.01$ vs. NC. 3'-UTR, 3'-untranslated region; IL-6, interleukin-6; NC, negative control; miR, microRNA.

stimulates the secretion of inflammatory mediators by $\mathrm{T}$ and B lymphocytes, promotes the maturation and differentiation of B lymphocytes and enhances the effects of IL-1 $\beta$ and TNF- $\alpha$ (30). In inflammatory responses, IL-6 has chemotaxis on other inflammatory cells including neutral lymphocytes and mononuclear macrophages (31). In the present study, the expression of IL-6 mRNA and protein in liver tissues, PBMCs and serum from patients with liver cirrhosis was higher than in patients with liver fibrosis, suggesting that inflammation may be aggravated during the transformation from liver fibrosis to cirrhosis. Upregulation of IL-6 may be caused by the activation of monocytes and lymphocytes, which can secrete abundant IL-6 factors and produce antigen immune responses (32).

As an important gene regulator, miR molecules participate in various pathophysiological processes, including the proliferation, invasion and metastasis of tumor cells, hypertension, diabetes or atherosclerosis $(33,34)$. The general function of miR molecules is to regulate the expression of their target genes $(33,34)$, however the expression and mechanism of action of miR in Hepatitis B remains unclear. miR-146 was the first miR identified to induce a regulatory effect in the immune response and is associated with a number of diseases. For example, the abnormal expression of miR-146a has been detected in autoimmune diseases, such as rheumatoid arthritis $(35,36)$. Furthermore, clinical and animal models of osteoarthritis suggest that miR-146a is associated with pain in osteoarthritis (37-39). Studies have demonstrated that a number of binding sites of NF- $\mathrm{kB}$ exist in the promoter region of miR-146a gene and that lipopolysaccharides, IL-1 and TNF- $\alpha$ all promote miR-146a expression in a NF- $\kappa \mathrm{B}$-dependent manner (40-42). In the current study, bioinformatics predicted that IL-6 may be a direct target gene of miR-146a. The results demonstrated that miR-146a was downregulated and IL-6 was upregulated in liver tissues and PBMCs from patients with liver cirrhosis compared with patients with liver fibrosis, suggesting that the immune system may negatively regulate the targeting of miR-146a on IL-6 by downregulating miR-146a expression. This suggests that miR-146a is not directly correlated with platelet count or serum albumin. Thus, the expression of IL-6 is enhanced and immune responses are generated. Similarly, it was demonstrated that miR-146a is downregulated and IL-6 is upregulated in the serum of patients with liver cirrhosis. This observation indicates that increased levels of IL-6 induced by elevated miR-146a in PBMCs may be released into the serum. Therefore, the levels of miR-146a and IL-6 in the serum indicate the degrees of inflammatory responses and tissue lesions during the transformation from liver fibrosis to cirrhosis. In conclusion, the current study suggests that the decrease of 
miR-146a expression in the liver tissues, peripheral blood and serum regulates the expression of IL-6, leading to changes in the levels of associated proteins that serve biological roles in the occurrence and development of the disease. The balance between miR-146a and IL-6 expression may determine the occurrence and development of immunity. In addition, miR-146a is stable in the blood, meaning that it may be used for diagnostic purposes.

\section{Acknowledgements}

The authors would like to thank Dr Tonglong $\mathrm{Xu}$, the president of the hospital, for his encouragement and advice. In addition, the authors would like to thank Dr Yongli Wei for his contribution to the writing of the manuscript.

\section{Funding}

The present study was supported by the Linyi People's Hospital.

\section{Availability of data and materials}

The datasets used and/or analyzed during the current study are available from the corresponding author on reasonable request.

\section{Author's contributions}

ZY and SY designed the study. ZY and YP performed the experiments. ZY and SY analyzed the data. All authors interpreted the results and prepared the manuscript. All authors read and approved the final manuscript.

\section{Ethics approval and consent to participate}

All procedures performed in the current study were approved by the Ethics Committee of Linyi People's Hospital (Linyi, China). Written informed consent was obtained from all patients or their parents, guardians or next of kin.

\section{Patient consent for publication}

Written informed consent for publication of any associated data and accompanying images were obtained from all patients or their parents, guardians or next of kin.

\section{Competing interests}

The authors declare that they have no competing interests.

\section{References}

1. Cabre A, Babio N,Lazaro I, Lázaro I, Bulló M, Garcia-Arellano A, Masana L and Salas-Salvadó J: FABP4 predicts atherogenic dyslipidemia development. The PREDIMED study. Atherosclerosis 222: 229-234, 2012.

2. Tawada A, Kanda T, Imazeki F and Yokosuka O: Prevention of Hepatitis B virus-associated liver diseases by antiviral therapy. Hepatol Int 10: 574-593, 2016.

3. de Franchis R, Hadengue A, Lau G, Lavanchy D, Lok A, McIntyre N, Mele A,Paumgartner G,Pietrangelo A, Rodés J, et al: EASL international consensus conference on Hepatitis B. 13-14 September, 2002 Geneva, Switzerland. Consensus statement (long version). J Hepatol 39 (Suppl 1): S3-S25, 2003.
4. Chen YC, Chu CM, Yeh CT and Liaw YF: Natural course following the onset of cirrhosis in patients with chronic Hepatitis B: A long-term follow-up study. Hepatol Int 1: 267-273, 2007.

5. Chu CM and Liaw YF: Hepatitis B virus-related cirrhosis: Natural history and treatment. Semin Liver Dis 26: 142-152, 2006.

6. Bataller R and Brenner DA: Liver fibrosis. J Clin Invest 115: 209-218, 2005.

7. Pinzani M: Liver fibrosis. Springer Semin Immunopathol 21: 475-490, 1999.

8. Safadi R and Friedman SL: Hepatic fibrosis-role of hepatic stellate cell activation. MedGenMed 4: 27, 2002.

9. Trepo C, Chan HL and Lok A: Hepatitis B virus infection. Lancet 384: 2053-2063, 2014.

10. Sun M and Kisseleva T: Reversibility of liver fibrosis. Clin Res Hepatol Gastroenterol 39 (Suppl 1): S60-S63, 2015.

11. Calvaruso V and Craxi A: Regression of fibrosis after HBV antiviral therapy. Is cirrhosis reversible? Liver Int 34 (Suppl 1): S85-S90, 2014

12. Jiang XI, Luo Y, Zhao S, Chen Q, Jiang C, Dai Y, Chen Y and Cao Z: Clinical significance and expression of microRNA in diabetic patients with erectile dysfunction. Exp Ther Med 10: 213-218, 2015.

13. Jia W, Wu Y, Zhang Q, Gao GE, Zhang C and Xiang Y: Expression profile of circulating microRNAs as a promising fingerprint for cervical cancer diagnosis and monitoring. Mol Clin Oncol 3: 851-858, 2015.

14. Graziano A, Lo Monte G, Piva I, Caserta D, Karner M, Engl B and Marci R: Diagnostic findings in adenomyosis: A pictorial review on the major concerns. Eur Rev Med Pharmacol Sci 19: $1146-1154,2015$.

15. Hayes $\mathrm{CN}$ and Chayama K: MicroRNAs as biomarkers for liver disease and hepatocellular carcinoma. Int J Mol Sci 17: 280, 2016.

16. Ichikawa Y, Joshita S, Umemura T, Shobugawa Y, Usami Y, Shibata S, Yamazaki T, Fujimori N, Komatsu M, Matsumoto A and Tanaka E: Serum Wisteria floribunda agglutinin-positive human Mac-2 binding protein may predict liver fibrosis and progression to hepatocellular carcinoma in patients with chronic hepatitis B virus infection. Hepatol Res 47: 226-233, 2017.

17. Liu Y, Cheng LS, Wu SD, Wang SQ, Li L, She WM, Li J, Wang JY and Jiang W: IL-10-producing regulatory B-cells suppressed effector T-cells but enhanced regulatory T-cells in chronic HBV infection. Clin Sci (Lond) 130: 907-919, 2016.

18. MacParland SA, Ma XZ, Chen L, Khattar R, Cherepanov V, SelznerM,FeldJJ,SelznerNandMcGilvray ID:Lipopolysaccharide and tumor necrosis factor alpha inhibit interferon signaling in hepatocytes by increasing ubiquitin-like protease 18 (USP18) expression. J Virol 90: 5549-5560, 2016.

19. Chang TS, Chen CL, Wu YC, Liu JJ, Kuo YC, Lee KF, Lin SY, Lin SE, Tung SY, Kuo LM, et al: Inflammation promotes expression of stemness-related properties in HBV-related hepatocellular carcinoma. PLoS One 11: e0149897, 2016.

20. Li C, Deng M, Hu J, Li X, Chen L, Ju Y, Hao J and Meng S: Chronic inflammation contributes to the development of hepatocellular carcinoma by decreasing miR-122 levels. Oncotarget 7: 17021-17034, 2016.

21. Chang L, Lan T, Wu L, Li C, Yuan Y and Liu Z: The association between three IL-6 polymorphisms and HBV-related liver diseases: A meta-analysis. Int J Clin Exp Med 8: 17036-17045, 2015.

22. Lan T, Chang L, Wu L and Yuan YF: IL-6 plays a crucial role in HBV infection. J Clin Transl Hepatol 3: 271-276, 2015.

23. Chinese Society of Hepatology, Chinese Medical Association; Chinese Society of Infectious Diseases, Chinese Medical Association: The guidelines of prevention and treatment for chronic Hepatitis B. Zhonghua Gan Zang Bing Za Zhi 13: 881-891, 2005 (In Chinese).

24. Livak KJ and Schmittgen TD: Analysis of relative gene expression data using real-time quantitative PCR and the 2(-Delta Delta C(T)) method. Methods 25: 402-408, 2001.

25. Badding MA, Schwegler-Berry D, Park JH, Fix NR, Cummings KJ and Leonard SS: Sintered indium-tin oxide particles induce pro-inflammatory responses in vitro, in part through inflammasome activation. PLoS One 10: e0124368, 2015.

26. Hunter CA and Jones SA: IL-6 as a keystone cytokine in health and disease. Nat Immunol 16: 448-457, 2015.

27. Tanaka T, Narazaki $M$ and Kishimoto T: IL-6 in inflammation, immunity, and disease. Cold Spring Harb Perspect Biol 6: a016295, 2014.

28. Baeuerle PA and Henkel T: Function and activation of NF-kappa B in the immune system. Annu Rev Immunol 12: 141-179, 1994. 
29. Tone M, Powell MJ, Tone Y, Thompson SA and Waldmann $\mathrm{H}$ : IL-10 gene expression is controlled by the transcription factors Sp1 and Sp3. J Immunol 165: 286-291, 2000.

30. Yao X, Huang J, Zhong H, Shen N, Faggioni R, Fung M and Yao Y: Targeting interleukin-6 in inflammatory autoimmune diseases and cancers. Pharmacol Ther 141: 125-139, 2014.

31. Luo Q, Ma X, Wahl SM, Bieker JJ, Crossley M and Montaner LJ: Activation and repression of interleukin-12 p40 transcription by erythroid Kruppel-like factor in macrophages. J Biol Chem 279: 18451-18456, 2004.

32. Aarstad HH, Vintermyr OK, Ulvestad E, Kross K, Heimdal JH and Aarstad HJ: In vitro-stimulated IL-6 monocyte secretion and in vivo peripheral blood $\mathrm{T}$ lymphocyte activation uniquely predicted 15-year survival in patients with head and neck squamous cell carcinoma. PLoS One 10: e0129724, 2015.

33. Varshney J and Subramanian S: MicroRNAs as potential target in human bone and soft tissue sarcoma therapeutics. Front Mol Biosci 2: 31, 2015.

34. Liz $\mathrm{J}$ and Esteller M: lncRNAs and microRNAs with a role in cancer development. Biochim Biophys Acta 1859: 169-176, 2016

35. Pauley KM, Satoh M, Chan AL, Bubb MR, Reeves WH and Chan EK: Upregulated miR-146a expression in peripheral blood mononuclear cells from rheumatoid arthritis patients. Arthritis Res Ther 10: R101, 2008.

36. Abou-Zeid A, Saad M and Soliman E: MicroRNA 146a expression in rheumatoid arthritis: Association with tumor necrosis factor-alpha and disease activity. Genet Test Mol Biomarkers 15 807-812, 2011
37. Yamasaki K, Nakasa T, Miyaki S, Yamasaki T, Yasunaga Y and Ochi M: Angiogenic microRNA-210 is present in cells surrounding osteonecrosis. J Orthop Res 30: 1263-1270, 2012.

38. Li X, Gibson G, Kim JS, Kroin J, Xu S, van Wijnen AJ and Im HJ: MicroRNA-146a is linked to pain-related pathophysiology of osteoarthritis. Gene 480: 34-41, 2011.

39. Li X, Kroin JS, Kc R, Gibson G, Chen D, Corbett GT, Pahan K, Fayyaz S, Kim JS, van Wijnen AJ, et al: Altered spinal microRNA-146a and the microRNA-183 cluster contribute to osteoarthritic pain in knee joints. J Bone Miner Res 28: 2512-2522, 2013

40. Curtale G, Citarella F, Carissimi C, Goldoni M, Carucci N, Fulci V, Franceschini D, Meloni F, Barnaba V and Macino G: An emerging player in the adaptive immune response: MicroRNA-146a is a modulator of IL-2 expression and activation-induced cell death in T lymphocytes. Blood 115: 265-273, 2010.

41. Taganov KD, Boldin MP, Chang KJ and Baltimore D: NF-kappaB-dependent induction of microRNA miR-146, an inhibitor targeted to signaling proteins of innate immune responses. Proc Natl Acad Sci USA 103: 12481-12486, 2006.

42. Larner-Svensson HM, Williams AE, Tsitsiou E, Perry MM, Jiang X, Chung KF and Lindsay MA: Pharmacological studies of the mechanism and function of interleukin-1beta-induced miRNA-146a expression in primary human airway smooth muscle. Respir Res 11: 68, 2010. 